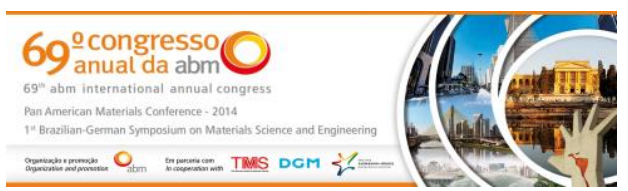

Tema: Gestão de meio ambiente e recuperação e tratamento de rejeitos

\title{
OTIMIZAÇÃO DE PROCESSO DE REGENERAÇÃO MECÂNICA DE AREIA FENÓLICA USADA DE FUNDIÇÃO*
}

\author{
Daniel Proszek ${ }^{1}$ \\ Carlos Alberto Mendes Moraes² \\ Wagnner dos Passos da Silva ${ }^{3}$ \\ Jacson de Castro ${ }^{4}$
}

\section{Resumo}

A globalização tem tornado o mercado internacional mais competitivo e o setor brasileiro de fundição cada vez mais é ameaçado pela produção asiática que oferece produtos com custos inferiores aos valores nacionais. O meio ambiente é outro fator emergente nos panoramas atuais, empresas com consciência ambiental sofrem com elevados custos para a disposição correta de materiais. Estes fatores são abordados no atual trabalho que focou na adequação de equipamento para regeneração mecânica de areia, tornando possível a reutilização do principal consumível de moldes de fundição. Tendo como base projeto inicial de equipamento de regeneração mecânica, foram aplicadas melhorias e posteriormente foram trabalhadas variações de parâmetros do processo. Oriunda do processo de cura a frio, a areia fenólica usada destorroada industrialmente foi testada variando a velocidade de rotação do atritor (450 e $900 \mathrm{RPM}$ ), e o tempo de permanência (10, 20 e $30 \mathrm{~min}$ ). Os experimentos em areia foram analisados através de distribuição granulométrica, análise de perda ao fogo e também a limpeza dos grãos via microscopia eletrônica de varredura, sempre guiados pelas referências de areia base e areia destorroada. Analisando os resultados encontrados foi possível identificar a influência das variáveis testadas e assim determinar a configuração mais eficiente na limpeza da capa resina que envolve grãos.

Palavras-chave: Fundição; Areia usada; Resina fenólica; Regeneração mecânica.

\section{PROCESS OPTIMIZATION FOR MECHANICAL RECLAMATION OF USED PHENOLIC SAND FROM FOUNDRY}

\begin{abstract}
Globalization has made the international market more competitive and the Brazilian casting industry is increasingly threatened by Asian manufacture that offers products at lower costs than national prices. The environment is also emerging in today's overview and conscious companies suffer with high costs for proper disposal of contaminated materials. These two subjects are discussed in the current project which is focused on the suitability of equipment for mechanical regeneration of sand, making possible the reuse of main consumable of casting mold. Based on the initial project of mechanical regeneration equipment, improvements have been applied and variations of process parameters were worked. Originating from the cold cure process, the used phenolic sand was tested by varying the rotation speed of the attritor (450 and $900 \mathrm{RPM})$, and time spent (10, 20, and $30 \mathrm{~min})$. The sand experiments were analyzed by particle size distribution, loss on ignition method and also the cleaning of grains by scanning electron microscopy, always guided by the baselines raw sand and phenolic sand. By analyzing of results it was possible to identify the influence of the variables tested and determine the most efficient configuration for cleaning of resin covering the grains.

Keywords: Foundry; Used sand; Phenolic resin; Mechanical reclamation.

Engenheiro Mecânico, Unisinos, São Leopoldo, RS, Brasil.

2 Engenheiro e Mestre em Engenharia dos Materiais, Doutor em Ciência dos Materiais, Professor Titular I, Coordenador do curso de Engenharia Ambiental, Unisinos, São Leopoldo, RS, Brasil.

3 Graduando em Engenharia Mecânica, Unisinos, São Leopoldo, RS, Brasil.

4 Graduando em Engenharia Mecânica, Unisinos, São Leopoldo, RS, Brasil.
\end{abstract}

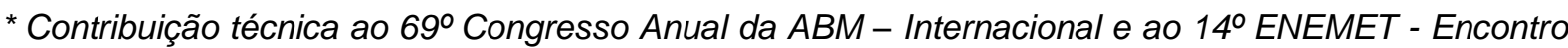
Nacional de Estudantes de Engenharia Metalúrgica, de Materiais e de Minas, 21 a 25 de julho de 2014, São Paulo, SP, Brasil. 


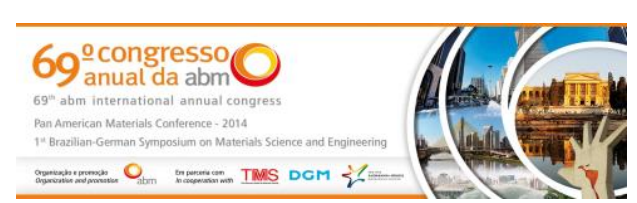

\section{INTRODUÇÃO}

A prática de fundição é integrante de cadeias produtivas em uma considerável parcela do ramo industrial. Através deste processo é possível a obtenção de peças nas mais variadas formas e dimensões. A produção mundial de fundidos em 2011 chegou na marca de 98,6 toneladas métricas e o Brasil ocupou a sétima posição no ranking mundial de maiores produtores do setor [1]. Apesar de empregar em seu processo produtivo grande parte de materiais metálicos reciclados, a indústria da fundição ainda é considerada poluidora devido à emissão de gases na atmosfera e por gerar considerável volume de resíduos, constituídos basicamente por areia com ligantes / aglomerantes orgânicos ou inorgânicos, classificados pela legislação brasileira como "não-inerte" (classe II-A) ou como resíduo "perigoso" (classe I) [2]. Estes fatores representam grande quantidade de areia descartada e além do impacto ambiental, o desperdício resulta em alto custo de logística e deposição do material descartado.

Buscando reduzir estas perdas inerentes ao processo, as empresas de fundição procuram alternativas para otimizar os desperdícios através da reutilização da areia. A regeneração desta areia é uma abordagem fundamental para a sobrevivência de plantas de fundição na atualidade, evitando assim descartes excessivos de areia e consequentemente reduzindo custos de fabricação.

Este trabalho prioriza a técnica para regeneração mecânica de areia fenólica usada de fundição oriunda do processo de cura a frio. O objetivo deste projeto é a determinação de parâmetros operacionais de um equipamento projetado para regeneração mecânica de areia fenólica oriunda dos processos de fundições, aplicando estudos para definir a condição ideal em relação à eficiência da máquina e de seu processo de reaproveitamento da areia.

\subsection{Revisão Bibliográfica}

\subsubsection{Fundição}

A técnica de fundir é definida como o conjunto de atividades requeridas para que metais em estado líquido sejam vazados em moldes com cavidades responsáveis por dar forma à liga quando solidificada novamente. Dentre os diversos tipos de classificação, o processo de fundição pode ser nomeado conforme seus moldes de fabricação, sendo eles permanentes quando feitos de metal ou consumíveis, constituídos basicamente por areia e agentes ligantes. A Figura 1 resume uma possível classificação do processo de fundição, levando em consideração apenas as sub-familias do processo [3].

\footnotetext{
* Contribuição técnica ao $69^{\circ}$ Congresso Anual da ABM - Internacional e ao 14ํㅡㄹ ENEMET - Encontro Nacional de Estudantes de Engenharia Metalúrgica, de Materiais e de Minas, 21 a 25 de julho de 2014, São Paulo, SP, Brasil.
} 

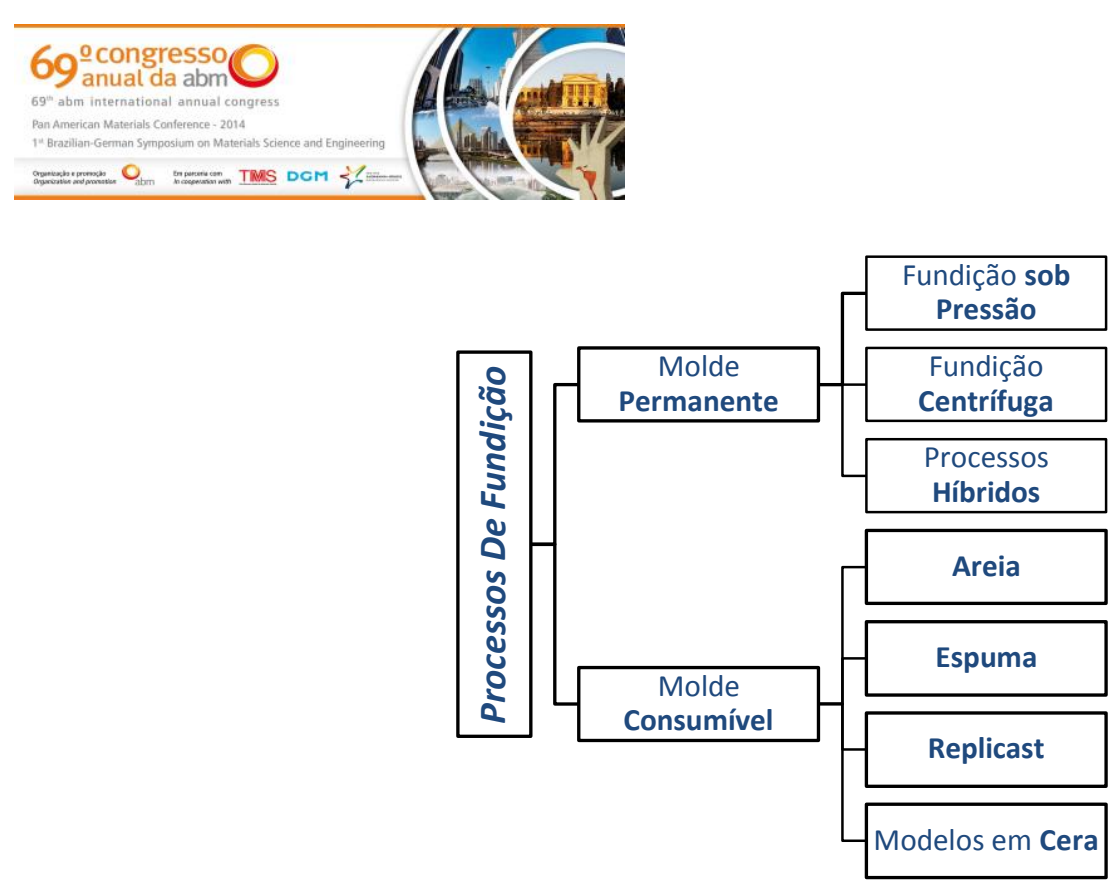

Figura 1. Classificação Básica dos Processos de Fundição [3]

\subsubsection{Areias de fundição}

O principal componente da areia de moldagem ou de macharia utilizada nas fundições é um agregado fino, mineralogicamente puro, denominado "areia-base" com granulometria que varia de $0,05 \mathrm{~mm}$ a $2,00 \mathrm{~mm}$ em seu diâmetro, sendo os tipos mais usados na indústria de fundição a areia de sílica (SiO2), de olivina ((MgFe)2SiO4), de zirconita ( $\mathrm{ZrSiO} 4)$ e de cromita (FeCr2O5 ou FeCr2O4) [4]. Para que a fundição seja realizada sobre as melhores condições possíveis e atendendo os requisitos do cliente, na seleção do molde é preciso analisar o tipo de metal a ser vazado, a característica do fundido a ser fabricado e também a disponibilidade dos aditivos e equipamentos para o processo escolhido [5].

\subsubsection{Aglomeração da areia}

Para manter os grãos unidos durante o processo de vazamento do metal líquido são adicionados aglomerantes na areia, estes materiais são responsáveis por evitar a destruição do molde quando em contato com o material quente, mantendo assim a estabilidade do processo até a conclusão da etapa de solidificação da peça. A força de ligação dos grãos também depende da umidade, temperatura e massa da areia além da adição de catalizadores para acelerar o processo de cura do molde [6]

A fundição com moldes em Areia Verde é o principal exemplo de utilização de aglomerantes inorgânicos, sendo a argila e o silicato de sódio os componentes utilizados no processo de fabricação destas caixas de fundir [7].

Os ligantes orgânicos são constituídos normalmente de resina ou óleo e foram desenvolvidos com intuito de resolver alguns problemas oriundos do processo de Areia Verde onde a velocidade de endurecimento é consideravelmente baixa, assim como o endurecimento, resistência e colapsibilidade do molde [7].

\subsection{Resina fenólica}

Este termo é utilizado para categorizar a grande maioria de produtos resultantes da reação de fenóis com aldeídos. Entre os diversos derivados fenólicos, o fenol propriamente dito é o componente mais empregado neste processo. O formol é a principal fonte dos aldeídos, sendo empregado em quase 100\% dos casos de geração da resina fenólica. O composto resultante desta reação formol com fenol pode estar na forma líquida ou sólida, sendo solúvel em vários tipos de solventes, sendo aplicado como isolante térmico ou para revestimentos a prova de água [6].

* Contribuição técnica ao $69^{\circ}$ Congresso Anual da ABM - Internacional e ao 14ํㅡㄹ ENEMET - Encontro Nacional de Estudantes de Engenharia Metalúrgica, de Materiais e de Minas, 21 a 25 de julho de 2014, São Paulo, SP, Brasil. 


\subsubsection{Excedentes de fundição}

Não fosse a presença de areia de macho, muitas areias descartadas pelas fundições poderiam ser classificadas como "inerte" (classe II-B) segundo a NBR 10.004. Entretanto, a maioria acaba sendo classificada como "não-inerte" (classe II-A), enquanto que algumas, por conter quantidades elevadas de torrões (que têm concentrações de fenóis superiores aos limites admissíveis na norma), são classificadas como resíduo "perigoso" (classe I) [2].

\subsubsection{Regeneração de areias de fundição}

A relação entre quantidade de areia e metal produzido no processo pode ser de 0,8 a 1,0, ou seja, para fabricação de um quilograma de fundido o molde necessita praticamente da mesma massa em areia. A regeneração permite a reutilização de areias provenientes do processo de moldagem e macharia, reconduzindo a areia usada às características de areia nova através da limpeza superficial de seus grãos [6]. A areia regenerada pode substituir totalmente ou parcialmente a areia nova e este processo de purificação pode ser aplicado por tratamento físico, químico, térmico ou então uma combinação entre os métodos [8].

Existem vários métodos de regeneração de areias de fundição devido ao grande número de processos para fabricação de moldes e machos. É preciso estabelecer uma clara distinção entre areia verde e areia ligada quimicamente para escolha do método ideal. Areias do processo de cura a frio podem ser regeneradas utilizando simples técnicas de tratamentos devido à fragilidade da camada do ligante. Sistemas de regeneração com atrição ou impacto podem ser aplicados neste caso [8].

Os sistemas de recuperação mecânica removem os revestimentos acumulados em torno dos grãos de areia utilizando choque, atrito e ar. Neste processo, a areia destorroada é disposta em um recipiente que sofre agitação mecânica com intuito de chocar os grãos entre si e também nas paredes do equipamento, efetuando assim a regeneração. Esta agitação da areia pode ser principalmente feita por atritores pneumáticos ou mecânicos rotativos [7].

No atritores mecânicos rotativos a areia é alimentada em um recipiente disposto de eixo motriz aletado que girando em velocidades parametrizadas faz a movimentação dos grãos de areia. Em alguns casos as aletas são fixadas no recipiente que girando faz com que os grãos de areia sejam arrastados e atritados. Nestes tipos de atritores a aceleração dos grãos é maior que no sistema pneumático, proporcionando assim maior redução das capas contaminantes, mas também aumentando a incidência de perdas por fratura dos grãos [8].

\section{MATERIAIS E MÉTODOS}

Os estudos visaram adequar e parametrizar equipamento de regeneração mecânica através de testes em areia fenólica usada de fundição. O equipamento utilizado para a regeneração mecânica foi desenvolvido dentro da UNISINOS como parte do projeto de pesquisa "Desenvolvimento tecnológico para regeneração combinada mecânico-térmico de areias fenólicas de fundição".

\subsection{Revisão do Equipamento}

O conceito do equipamento consiste na eliminação da resina dos grãos através do batimento da areia contra superfícies capazes de quebrar esta capa. Uma vez que as aletas e a panela giram de maneira simultânea por estarem unidas por solda,

\footnotetext{
* Contribuição técnica ao $69^{\circ}$ Congresso Anual da ABM - Internacional e ao 14ํㅡㄹ ENEMET - Encontro Nacional de Estudantes de Engenharia Metalúrgica, de Materiais e de Minas, 21 a 25 de julho de 2014, São Paulo, SP, Brasil.
} 
notou-se que o processo não estava purificando os grãos para reutilização (Figura 2). O movimento rotacional exercia sobre a areia contaminada uma força centrifuga que acabava jogando todos os grãos para a periferia da panela, ocasionando acúmulo nesta região. Além disso, a massa de todo o conjunto em movimento rotacional resultou em vibração considerável do equipamento. Estes fatores eliminaram praticamente todos os choques do material a ser limpo e também impediram o funcionamento do equipamento por intervalos maiores que 5 minutos devido à vibração.

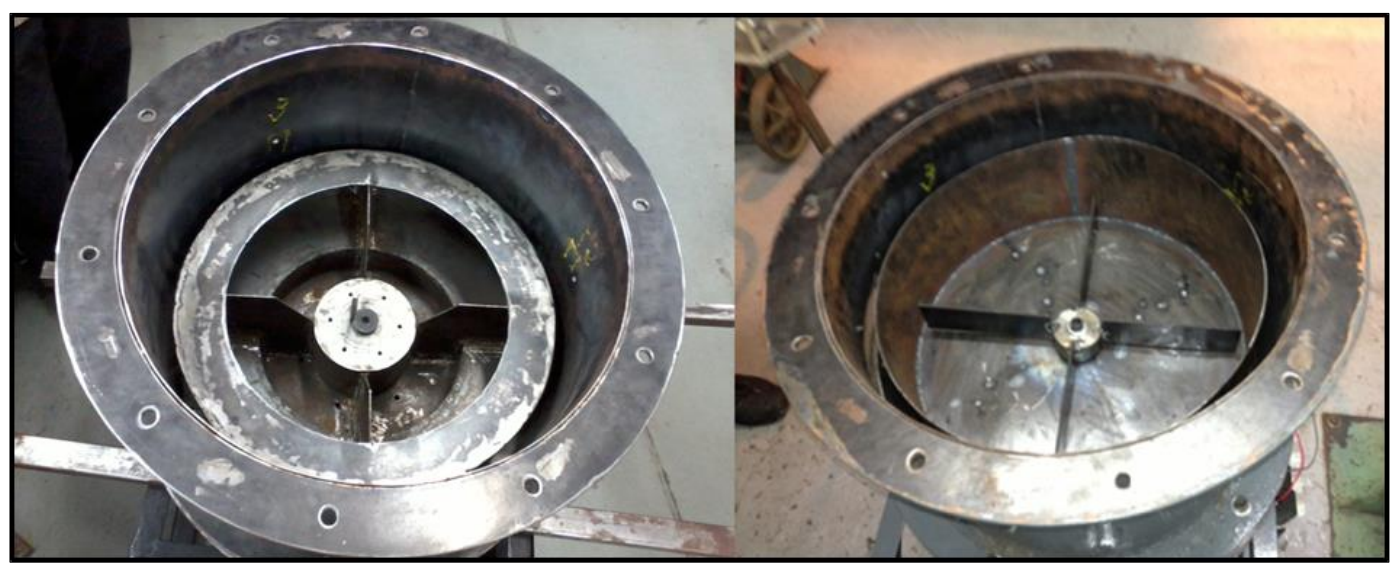

Figura 2. Conceitos Inicial e Revisado da Panela de Regeneração

No sistema revisado o conjunto panela + aletas passou a trabalhar separadamente, a panela com aletas soldadas foi substituída por um recipiente de volume similar, porém agora preso na carenagem do equipamento e sem ligação com as pás. As quatro aletas do novo conceito estão distribuídas simetricamente e soldadas sobre uma bucha acoplada a um eixo motriz, responsável pelo giro independente das pás em relação à panela.

\subsection{Parâmetros de Regeneração}

O plano de experimentos foi estruturado a modo de que, após a série de testes realizados, fosse possível identificar qual a melhor composição de parâmetros testados no estudo, obtendo assim a maior eficiência de operação do equipamento. A primeira análise realizada é quanto à disponibilidade e flexibilidade do teste, o novo conceito do regenerador mecânico disponibiliza três condições individuais de alteração para parâmetros:

- Quantidade de areia a ser regenerada, com limite de $8 \mathrm{Kg}$;

- Rotação do conjunto de pás, com limite de 900 RPM;

- Tempo de regeneração, sem limite.

Com base nestas premissas e também considerando que o equipamento nunca fora testado anteriormente, a condição inicial foi estimada na quantidade de $5 \mathrm{~kg}$ de areia sendo regenerada com rotação do eixo motriz em 900 RPM. O tempo inicial de regeneração de 5 minutos foi estimado com intuito de verificar possíveis vibrações da máquina, problema identificado na versão anterior do projeto. Uma vez que este problema não foi identificado, o regenerador atuou em condições normais por mais 5 minutos. A partir do try-out foi possível determinar os parâmetros de testes que estão descritos na Tabela 1.

Tabela 1. Definição de Parâmetros de Testes

* Contribuição técnica ao $69^{\circ}$ Congresso Anual da ABM - Internacional e ao 14ํㅡㄹ ENEMET - Encontro Nacional de Estudantes de Engenharia Metalúrgica, de Materiais e de Minas, 21 a 25 de julho de 2014, São Paulo, SP, Brasil. 


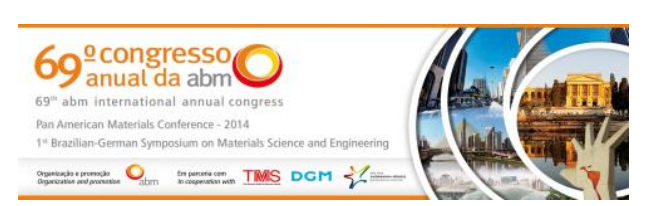

\begin{tabular}{l|ccc} 
Experimento & $\begin{array}{c}\text { Quant. } \\
{[\mathrm{kg}]}\end{array}$ & $\begin{array}{c}\text { Rotação } \\
{[\mathrm{RPM}]}\end{array}$ & $\begin{array}{c}\text { Tempo } \\
{[\mathrm{min}]}\end{array}$ \\
\hline Experimento 1 & 5 & 900 & $5+5$ \\
\hline Experimento 2 & 3 & 900 & 10 \\
Experimento 3 & 3 & 900 & 20 \\
Experimento 4 & 3 & 900 & 30 \\
\hline Experimento 5 & 3 & 450 & 10 \\
Experimento 6 & 3 & 450 & 20 \\
Experimento 7 & 3 & 450 & 30 \\
\hline
\end{tabular}

É importante salientar que para cada um dos experimentos a areia foi totalmente removida do equipamento e armazenada em sacos plásticos, ou seja, para cada teste foi colocada uma quantidade nova de $3 \mathrm{~kg}$ de areia destorroada.

\subsection{Métodos de Análise da Areia Regenerada}

A análise dos resultados dos parâmetros aplicados foi desenvolvida através de ensaios de granulometria, análise perda ao fogo e análise microscópica.

O ensaio de granulometria foi realizado conforme NBR NM 248 (2003) visando identificar a distribuição granulométrica, módulo de finura e dimensão característica dos grãos.

O método de perda ao fogo está baseado na norma da ABNT 1988 conforme NBR 10178 e objetiva determinar o teor de material orgânico contido em areias e outros materiais de fundição.

A eficiência do equipamento foi determinada conforme o percentual de perda ao fogo (Equação 1) obtido antes e após o processo de regeneração da areia contaminada com resina fenólica [9].

Onde:

$$
\%=\frac{P F_{U}-P F_{R}}{P F_{U}} * 100
$$

\% Eficiência do tratamento mecânico de acordo com perda ao fogo

$\mathrm{PF}_{\mathrm{u}}$ - Perda ao fogo areia usada;

$P F_{R}$ - Perda ao fogo areia regenerada;

A microscopia eletrônica de varredura (MEV) consiste em "capturar" imagens de qualquer material sólido com elevada resolução e nitidez, nesse caso, podendo visualizar as formas dos grãos analisados. Assim, pode-se definir a morfologia dos grãos dos resíduos e agregados. O equipamento utilizado no ensaio do MEV foi um modelo EVO MA15 da marca ZEISS, realizado pelo laboratório Itt Fossil da Unisinos.

\section{RESULTADOS E DISCUSSÃO}

A análise de resultados deste trabalho será apresentada da seguinte maneira: alteração de projeto, análise granulométrica, análise de perda ao fogo e análise via MEV.

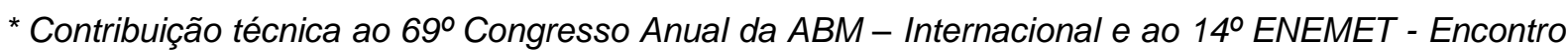
Nacional de Estudantes de Engenharia Metalúrgica, de Materiais e de Minas, 21 a 25 de julho de 2014, São Paulo, SP, Brasil.
} 


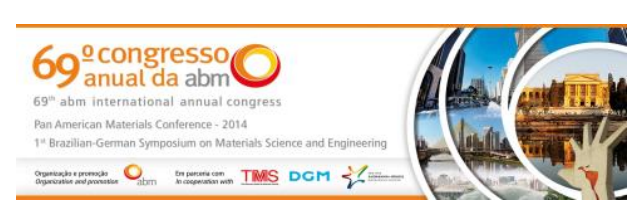

\subsection{Alteração de Projeto}

As alterações tornaram o regenerador mais simples e otimizado, eliminando completamente a vibração do equipamento. Este fato está basicamente atrelado a diferença de massa entre projeto final e projeto revisado mas também ao possível desbalanceamento do conjunto. No primeiro caso, a massa da panela em rotação era de aproximadamente $10 \mathrm{~kg}$. Na melhoria aplicada, a massa em rotação reduziu para $1,5 \mathrm{~kg}$ uma vez que apenas as pás entram em giro e a panela é fixada ao equipamento.

Não foi possível atingir conclusões significativas do primeiro conceito pois a vibração ocasionou a parada dos testes. As análises deste processo identificaram apenas pequenas variações granulométricas, problema relacionado à aglomeração da areia quando posta em giro. Por ser um sistema único, a força centrífuga apenas acumulou os grãos sem promover grandes choques entre eles ou atritos na panela. O conceito revisado permitiu a colisão e atrição dos grãos entre si próprios e também sobre paredes rígidas do equipamento, sendo estas paredes a carenagem metálica da panela e as pás de regeneração.

\subsection{Caracterização Granulométrica}

A Figura 3 mostra o resultado de granulometria para os 6 experimentos realizados contendo $3 \mathrm{~kg}$ de areia cada, sendo eles comparados com a distribuição de grãos para areia base e areia não regenerada. Para a maior rotação (900 RPM) é possível notar retenção relevante nas peneiras de malha \#100 e \#140, fator que representa um aumento na quantidade de grãos quebrados. Para experimentos 5, 6 e 7, que possuem rotação de 450 RPM, ocorreu considerável retenção na malha \#50, representando percentual maior que a areia destorroada.

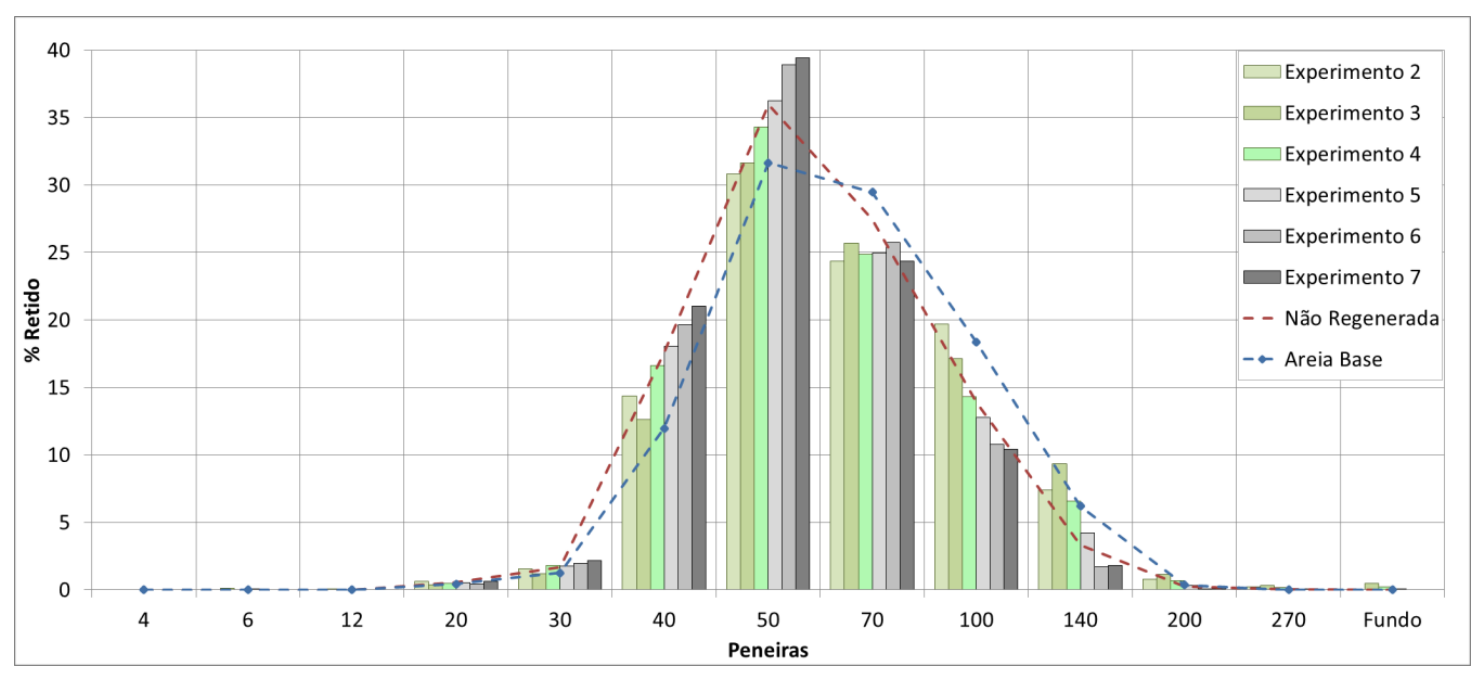

Figura 3. Análise Granulométrica

Quando comparados a areia base, o experimento 3 é aquele que possui maior similaridade quanto a distribuição granulométrica e a peneira \#70 possui a maior variação de retenção dos grãos, mas esta diferença entre as amostras não chega a atingir a faixa de $4 \%$.

Através da Figura 4 é possível notar maior incidência de finos nas regenerações aplicadas com 900 RPM, o experimento 3 possui maior representatividade e contém o dobro da quantidade de finos do experimento 4. A baixa rotação manteve os

\footnotetext{
* Contribuição técnica ao $69^{\circ}$ Congresso Anual da ABM - Internacional e ao 14ํㅡㄹ ENEMET - Encontro Nacional de Estudantes de Engenharia Metalúrgica, de Materiais e de Minas, 21 a 25 de julho de 2014, São Paulo, SP, Brasil.
} 

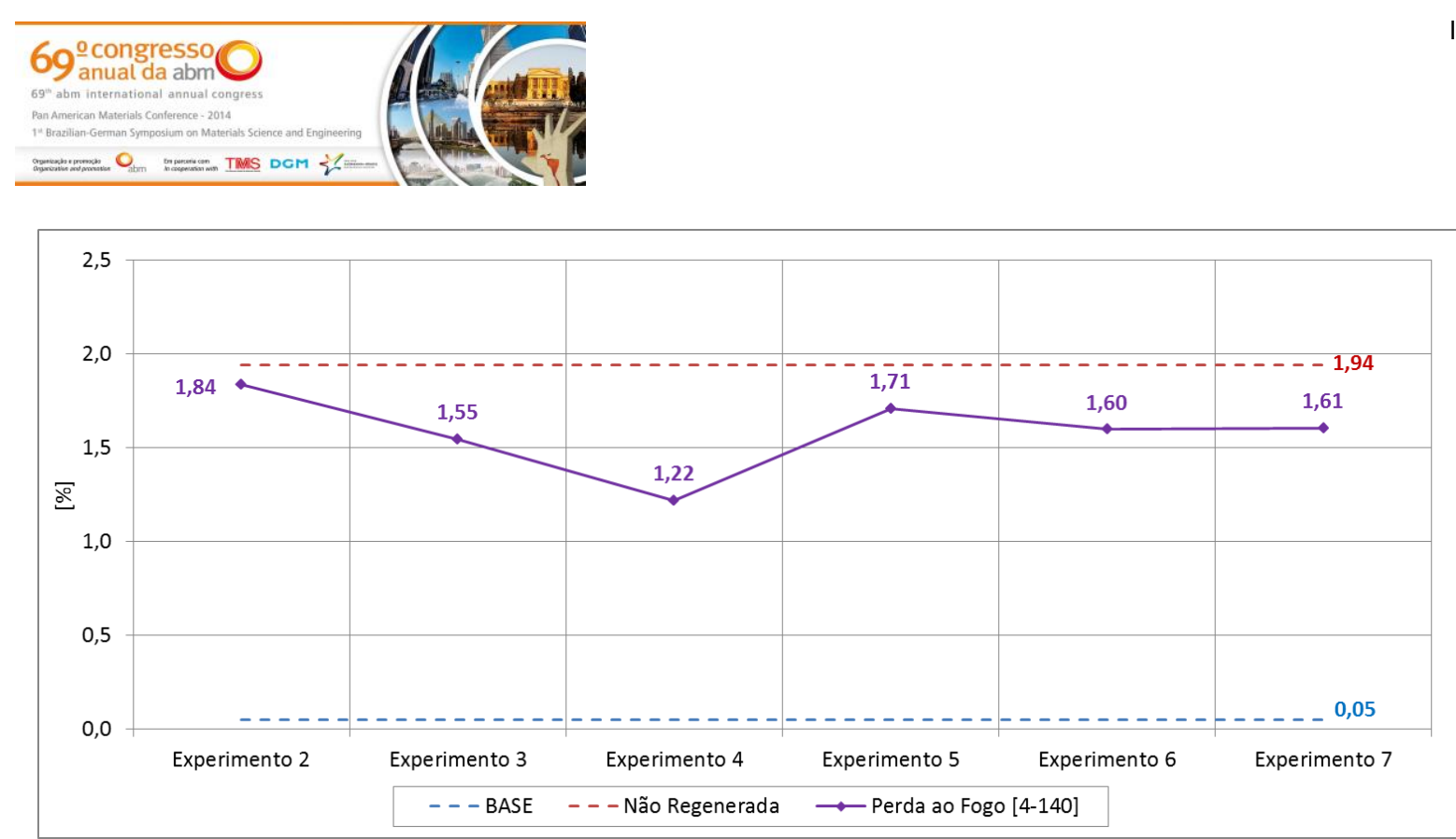

Figura 5. Análise de perda ao fogo desconsiderando presença de finos

Considerando a Equação (1) é possível determinar as eficiências de regeneração pela análise de perda ao fogo. O experimento 4 foi a amostra com 0 melhor resultado possuindo uma eficiência de $37 \%$.

\subsection{Morfologia e Grau de Limpeza via MEV}

O microscópio eletrônico de varredura permitiu a análise visual aprofundada das amostras, foi possível verificar em aumentos de 100X e 300X que todos os experimentos eliminaram parcialmente a resina, mas nunca totalmente. Em experimentos com 900 RPM a resina remanescente está distribuída de forma granulométrica sobre os grãos de areia, com rotações de 450 RPM o ligante está aglomerado em áreas concentradas. A Figura 6 mostra, para rotação de 900RPM, pequenos pontos de contaminação ao longo de toda superfície dos grãos, por outro lado os grãos submetidos à rotação de 450 RPM possuem áreas maiores de limpeza de grãos, mas em contrapartida também apresentam grandes regiões de acumulo da resina.

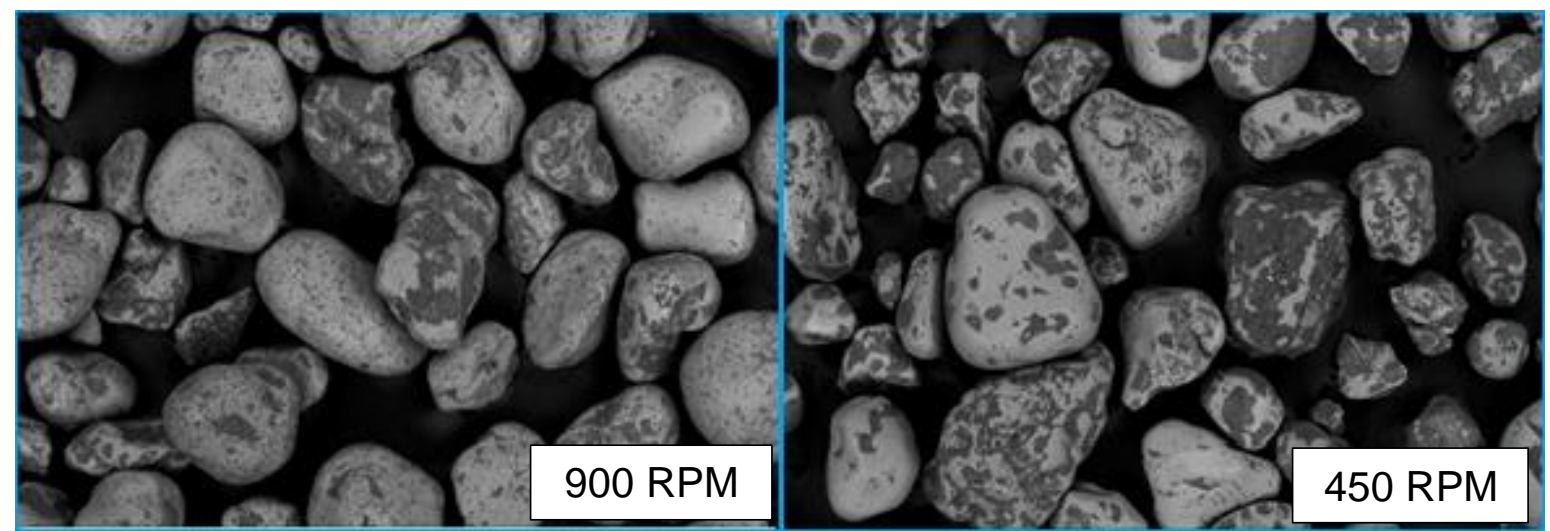

Figura 6. Distribuição de Resina Remanescente

Quanto aos critérios visuais, o tempo de regeneração e a rotação influenciaram na remoção da resina onde períodos mais longos resultaram em maiores remoções do aglomerante, consequentemente a rotação de 900 RPM demonstrou eliminação maior de resina conforme aumento de tempo.

\footnotetext{
* Contribuição técnica ao 69 Congresso Anual da ABM - Internacional e ao 14ํㅡㄹ ENEMET - Encontro Nacional de Estudantes de Engenharia Metalúrgica, de Materiais e de Minas, 21 a 25 de julho de 2014, São Paulo, SP, Brasil.
} 


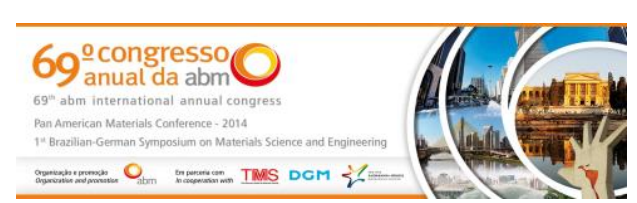

\section{CONCLUSÃo}

O novo método de atritor mecânico rotativo eliminou a vibração do equipamento, tornando possível o processo de regeneração e avaliação de variações de rotação e tempo aplicados em quantidades de $3 \mathrm{~kg}$ de areia por análise.

O impacto das variações de parâmetros foram estudadas nas análises laboratoriais aplicadas. O experimento 3 foi aquele com maior proximidade da areia base em relação a distribuição granulométrica, possuindo maior retenção de grãos com dimensões de 0,3 (\#50) e 0,425 mm (\#40). Por outro lado este experimento representou maior módulo de finura e teor de finos, indícios de maior esfarelamento de grãos e também da retirada de resina. Os experimentos com menor rotação apresentaram estes índices mais baixos que a areia destorroada.

Através da perda ao fogo foi possível estimar a eficiência de cada parâmetro de regeneração e o experimento 4 foi aquele que obteve o melhor resultado quando desconsiderando as últimas 3 peneiras (os finos). A eficiência de regeneração dos parâmetros desta amostra é de 37\%, valor inferior aos encontrados por Mariotto [9] (Tabela 6, pg. 48) que sugere a faixa de 80 a 95\%, porém superiores aos estudos práticos de Moosher [10] que obteve $22 \%$ de eficiência em regenerador mecânico.

A comparação mais complexa está em torno da morfologia e grau de limpeza via $\mathrm{MEV}$, apresentando pequena vantagem sobre os outros testes, os experimentos $3 \mathrm{e}$ 4 mais uma vez se destacam quanto a eliminação das capas de resina. Estas amostras apresentam resinas pontuais nos grãos enquanto amostras de rotações mais baixas mantiveram áreas maiores de contaminação.

Com base nestas considerações finais é possível afirmar que o novo conceito do regenerador mecânico é capaz de promover a limpeza parcial dos grãos, confirmando resultados obtidos por Leandro Moosher [10] e Rodrigo Gaspar [11]. A regeneração em baixa rotação apresentou tendência de melhores resultados se aplicada durante maior tempo. Porém, entre os melhores resultados obtidos, 0 experimento 4 possui maior representatividade uma vez que sua eficiência gira em torno de $37 \%$ quando calculada pela análise de perda ao fogo.

\section{Agradecimentos}

À UNISINOS, por disponibilizar recursos suficientes para desenvolvimento completo deste trabalho nas dependências da universidade.

À empresa Metalúrgica Lorscheitter pela amostras estudadas, e ao CNPq pelo apoio financeiro ao projeto maior.

\section{REFERÊNCIAS}

1 Modern Casting: A publication of the American Foundry Society. Estados Unidos: BPA, dez. 2012. Disponível em: <http://www.afsinc.org/multimedia/

modernCasting.cfm?navltemNumber=511>. Acesso em: 24 jul. 2013.

2 Hotta CM. Estudo da Geração de Resíduos Sólidos em Indústria de Fundição. 2011. 46 f. Trabalho de Conclusão de Curso (Bacharel em Engenharia de Produção) - Curso de Engenharia de Produção, UNISEB-COC, Ribeirão preto, 2011.

3 ASM Metals Handbook: Casting. Volume 15. ed. 4. Estados Unidos: McGraw-Hill Book Co, 1996.

4 Marino R. Utilização de areia de fundição em concreto. Projeto premiado pela Bayer "Prêmio de Meio Ambiente". USP, 2003.

\footnotetext{
* Contribuição técnica ao $69^{\circ}$ Congresso Anual da ABM - Internacional e ao 14ํㅡㄹ ENEMET - Encontro Nacional de Estudantes de Engenharia Metalúrgica, de Materiais e de Minas, 21 a 25 de julho de 2014, São Paulo, SP, Brasil.
} 


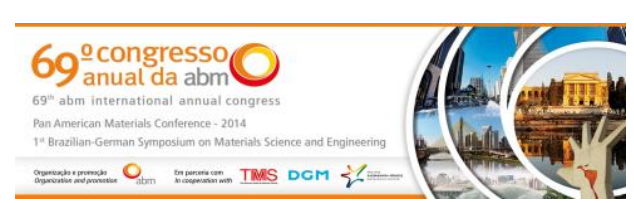

5 Chiaverini V. Tecnologia Mecânica: Processos de Fabricação e Tratamento. Volume 2. São Paulo: McGraw-Hill Ltda, 1986.

6 Scheunemann R. Regeneração de Areia de Fundição Através de Tratamento Químico Via Processo Fenton. 2005. 71 f. Dissertação (Mestrado em Engenharia Química) Programa de Pós-Graduação em Engenharia, Universidade Federal de Santa Catarina, Florianópolis, 2005.

7 Moreira MTP. Contaminação Ambiental Associada às Areias Residuais de Fundição. 2004. 218 f. Dissertação (Doutorado em Engenharia Química) - Programa de PósGraduação em Engenharia, Universidade do Porto, porto, 2004.

8 The European IPPC (Integrated Pollution Prevention and Control) Bureau, Reference Document on Best Available Techniques in the Smitheries and Foundries Industry. Mai. 2005. Disponível em < http://eippcb.jrc.ec.europa.eu/reference/ >. Acesso em: 27 jul. 2013.

9 Mariotto CL. Regeneração de Areias de Fundição. Instituto de Pesquisas Tecnológicas do Estado de São Paulo S.A, 2001.

10 Moosher L. Renegeração de Areia de Fundição por método termo-mecânico. 2009. 54 f. Trabalho de Conclusão de Curso (Bacharel em Engenharia Mecânica) Curso de Engenharia Mecânica, Universidade do Vale do Rio do Sinos (UNISINOS), São Leopoldo, 2009.

11 Gaspar RC, et al. Caracterização de areia de fundição via tratamento de regeneração termo-mecânico. Artigo apresentado no 62ํㅡㄹ Congresso Anual da ABM. Vitória/ES, 24 a 28 de julho de 2007.

* Contribuição técnica ao 69ำ Congresso Anual da ABM - Internacional e ao 14ํㅡㄹ ENEMET - Encontro Nacional de Estudantes de Engenharia Metalúrgica, de Materiais e de Minas, 21 a 25 de julho de 2014, São Paulo, SP, Brasil. 